\title{
Sensitivity of wheat yields to rise in growing season temperature: Evidences from panel data analysis
}

\author{
K. PHILIP ${ }^{1}$, S.S. ASHA DEVI ${ }^{1}$, G.K. JHA ${ }^{1 *}$, B.M.K. RAJU ${ }^{2}$, B.SEN ${ }^{1}$, A. ALI ${ }^{3}$ and J. KUMARI \\ ${ }^{1}$ Division of Agricultural Economics, ICAR-IARI, New Delhi- 110012 \\ ${ }^{2}$ Section of Design and Analysis, ICAR-CRIDA, Hyderabad - 500059 \\ ${ }^{3}$ Division of Biochemistry, ICAR-IARI, New Delhi -110012 \\ ${ }^{4}$ Division of Germplasm Evaluation, ICAR-NBPGR, New Delhi - 110012 \\ ${ }^{*}$ Corresponding author: girish.stat@gmail.com
}

\begin{abstract}
The impact of climate change on agriculture is well studied yet there is scope for improvement as crop specific and location specific impacts need to be assessed realistically to frame adaptation and mitigation strategies to lessen the adverse effects of climate change. Many researchers have tried to estimate potential impact of climate change on wheat yields using indirect crop simulation modeling techniques. Here, this study estimated the potential impact of climate change on wheat yields using a crop specific panel data set from 1981 to 2010 , for six major wheat producing states. The study revealed that $1{ }^{\circ} \mathrm{C}$ increase in average maximum temperature during the growing season reduces wheat yield by 3 percent. Major share of wheat growth and yield $(79 \%)$ is attributed to increase in usage of physical inputs specifically fertilizers, machine labour and human labour. The estimated impact was lesser than previously reported studies due to the inclusion of wide range of short-term adaptation strategies to climate change. The results reiterate the necessity of including confluent factors like physical inputs while investigating the impact of climate factors on crop yields.
\end{abstract}

Key words: Climate change, wheat, panel data

Indian agriculture showed an impressive growth over last decades that made the country self-sufficient in terms of food grain production. However, ensuring food security for the burgeoning population using depleting resource base under the risks of climate change is a challenge for a country like India where $52 \%$ of the net sown area is still unirrigated and rainfed. Changes in precipitation and temperature of most locations have reduced the average yields and increase variability in production with implications on food security (Nelson et al., 2009), that include both direct nutritional effects and livelihood effects (Swaminathan et al., 2012). But, food production systems across world respond to climate change in different ways, as some countries in the temperate zones may be benefitted from climate change while many countries in the tropical and sub-tropical zones appear more vulnerable (Rosenzweig and Parry, 1994). Hence it is relevant to study location specific effects of climate change on agriculture.

Wheat is one of the staple grains in India with a monthly consumption of $4.25 \mathrm{~kg}$ per person in rural India and $4.00 \mathrm{~kg}$ per person in urban areas. It is often stated that wheat cultivation in India is a "gamble of temperature"
(Howard, 1924). During past four decades India's surface temperature has increased by $0.3^{\circ} \mathrm{Cand}$ is expected to increase by $1-4^{\circ} \mathrm{C}$ with the turn of the 21 st century (DEFRA, 2005). Temperature optima for wheat is $\sim 22^{\circ} \mathrm{C}$ for vegetative development and $21^{\circ} \mathrm{C}$ for reproductive development, while $\sim 35.4^{\circ} \mathrm{C}$ is the maximum limit for grain filling (Porter and Gawith, 1999). Wheat yields are projected to decrease due to rise in temperature in areas with mean seasonal maximum and minimum temperatures in excess of $27^{\circ} \mathrm{C}$ and $13^{\circ} \mathrm{C}$, respectively (Kumar et al., 2014). Rise in growing season temperatures had been reported to reduce growing season length, leading to decline in wheat productivity. Several studies tried to estimate the impact of climate change on wheat productivity (Attri and Rathore, 2003; Jalota et al., 2013; Zaccharias et al., 2014; Kumar et al., 2014; Pramod et al., 2017) but they made use of indirect estimation procedures like crop simulation models which may ignore influence of many variables that influence crop production in on-farm conditions. Only a few studies have used direct estimation procedures (Birthal et al., 2014; Jha and Tripathi, 2017) using observed field data. However, these studies have failed to segregate the impact of climate and nonclimate factors on wheat productivity and often incorrectly 
approximate the latter's contribution as a linear trend $(\mathrm{Gu}$, 2003), leading to over estimation of the coefficients.

Conventionally used simulation models failed to account for the full range of on-farm adaptations followed by farmers to minimize the impact of climate change (Blanc and Schelkner, 2017). An alternative approach to assess the impact of climate change is the Ricardian model based on hedonic pricing principle and competitive land markets (Mendelsohn et al., 1994). However, Ricardian models tend to provide biased estimates in the absence of data on confounding factors (Deschenes and Greenstone, 2007). Panel data regression models have been used to assess the potential impact of climate change as they account for onfarm adaptation to climate change and arenot subjected to omitted variable bias (Blanc and Schelkner, 2017).

With this background, the study attempted to quantify the impact of rise in temperature and rainfall variability on wheat productivity while controlling for non-climate factors using a crop specific panel data for six major wheat growing states from 1981-2010.

\section{MATERIALS AND METHODS}

The analysis comprises of three sections. Initially,trends in climate variables during the study period were analyzed. Further the potential impact of climate change on wheat yields was estimated using a panel data regression model. The potential contribution of non-climate factors to wheat yield growth was computed which validates the necessity of including non-climate factors while estimating potential impact of climate change in direct estimation techniques.

Climate data for the study were derived using $0.50 \times 0.50$ grid data set of rainfall and $10 \times 10$ grid data set of maximum and minimum temperature sourced from the India Meteorological Department (IMD). The daily data on maximum and minimum temperature were transformed into averages for the crop growing season and daily rainfall was converted into cumulative rainfall for the crop growing season. Both average maximum temperature (a proxy for day time temperature) and average minimum temperature (a proxy for night time temperature)were included in the model to capture differential impact of day and night temperatures. As majority of the wheat crop is grown under irrigated conditions, fluctuations in rainfall are more likely to impact wheat yields rather than average rainfall, thus this study included the deviation from normal rainfall as an explanatory variable in our analysis to capture the effects of excessive fluctuations. Wheat is cultivated exclusively in the Rabi season and the wheat growing period is approximated to span from November to March in line with previous studies (Birthal et al., 2014).

The data on wheat yield was compiled from various publications of Directorate of Economics and Statistics, GOI. The data on inputs used per hectare was obtained from various issues of the Commission on Agricultural Costs and Prices (CACP), DES, GOI(1980-2010). Input usage wasexpressed in terms of per hectare expenses at constant price for all inputs except for fertilizers which was expressed in kilogram per hectare.

\section{Model}

To establish the empirical relationship between climate change and wheat yields, a panel data approach was employed. A fixed effects model was selected wherein spatial fixed effects were used to control for location specific and time invariant factors influencing wheat yields. Non-climate factors were also included to segregate their potential impact on wheat yield growth and account for changes in input usage in response to climate change.

The wheat yield function is estimated as:

$\ln Y_{i t}=\alpha+\sum_{j=1}^{5} \beta_{j} * \ln X_{j i t}+\sum_{k=1}^{3} W_{k} * C_{k i t}+\sum_{i=2}^{6} \delta_{i} * D_{i}+\mu_{i t}$

where $Y_{\text {it }}$ is wheat yield of $i^{\text {th }}$ state in year $t, X_{j i t}$ is the value of $\mathrm{j}^{\text {th }}$ input for state $\mathrm{i}$ in year $\mathrm{t}, \mathrm{C}_{\mathrm{kit}}$ is the value of $\mathrm{k}^{\text {th }}$ climate variable for state $i$ in year $t, D_{i}$ is a state specific dummy, $\mu_{\mathrm{it}}$ is the error term and $\alpha, \beta, \mathrm{W}$ and $\delta$ are the parameters to be estimated.In log linear specification, the coefficients of the climate variables are to be interpreted as relative changes in yield arising out of absolute change in climate variable while the input coefficients are interpreted as elasticity.

\section{RESULTS AND DISCUSSION}

\section{Trend analysis of climate variables}

Trends in climate variables namely average maximum temperature, average minimum temperature and total rainfall were computed and the results are tabulated in Table 1. All states except Bihar registered a statistically significant rise in maximum average temperature. Maximum temperature (a proxy for day temperature) had risen by $0.6^{\circ} \mathrm{C}$ in Punjab with an annual growth rate of $0.02^{\circ} \mathrm{C}$ which wasthe highest in the wheat growing belt. Maximum temperature had risen by $0.27^{\circ} \mathrm{C}, 0.45^{\circ} \mathrm{C}, 0.47^{\circ} \mathrm{C}$ and $0.51^{\circ} \mathrm{C}$ in Uttar Pradesh, 
Table 1: Trend analysis of climate variables from 1981-2010

\begin{tabular}{llll}
\hline State & Maximum temperature & Minimum temperature & Rainfall \\
\hline Punjab & $0.0208^{* * *}$ & $0.0511^{* * *}$ & -0.1475 \\
& $(0.6043)$ & $(1.4829)$ & $(-4.2786)$ \\
Haryana & $0.0177^{* * *}$ & $0.0467 * * *$ & 0.0097 \\
& $(0.5143)$ & $(1.3557)$ & $(0.2814)$ \\
Uttar Pradesh & $0.0093^{*}$ & $0.0347^{* * *}$ & -0.1760 \\
& $(0.2700)$ & $(1.0071)$ & $(-5.1029)$ \\
Madhya Pradesh & $0.0155^{* * *}$ & $0.0309^{* * *}$ & -0.1626 \\
& $(0.4500)$ & $(0.8971)$ & $(-4.7143)$ \\
Rajasthan & $0.0163 * * *$ & $0.0428 * * *$ & -0.0983 \\
& $(0.4728)$ & $(1.2400)$ & $(-2.8500)$ \\
Bihar & 0.0063 & $0.0464 * * *$ & -0.2379 \\
& $(0.1828)$ & $(1.3457)$ & $(-6.8986)$ \\
\hline
\end{tabular}

Note: Figures in parentheses are cumulative effects; ${ }^{* *}$ indicates $1 \%$ level of significance, ${ }^{* *}$ indicates $5 \%$ level of significance and $*$ indicates $10 \%$ level of significance

Madhya Pradesh, Rajasthan and Haryana respectively during the study period. All states experienced a statistically significant increase in minimum temperature (a proxy for night temperatures). The highest increase in minimum temperature was observed in Punjab $\left(1.4^{\circ} \mathrm{C}\right)$ followed by Haryana $\left(1.35^{\circ} \mathrm{C}\right)$, Bihar $\left(1.34^{\circ} \mathrm{C}\right)$, Uttar Pradesh $\left(1.0^{\circ} \mathrm{C}\right)$ and Madhya Pradesh $\left(0.87^{\circ} \mathrm{C}\right)$. The annual growth rates in minimum temperature are $0.05^{\circ} \mathrm{C}, 0.04^{\circ} \mathrm{C}, 0.03^{\circ} \mathrm{C}, 0.04^{\circ} \mathrm{C}$ and $0.04^{\circ} \mathrm{C}$ in Punjab, Haryana, Uttar Pradesh, Madhya Pradesh, Rajasthan and Bihar respectively. Rabi rainfall on the other hand not recorded a significant increase in any of the states during the study period. This justifies our decision to include deviations in rainfall in place of cumulative rainfall in the crop yield function.

\section{Crop response function estimation}

Prior to estimation of the crop yield function, stationarity of dependent and independent variables was checked using the Im- Pesaran-Shin test. All variables were found to be stationary. The model was initially estimated using ordinary least square technique. The residuals obtained were subjected to various residual diagnostics tests. The normality assumption was checked by plotting a Kernel density plot of residuals against a standard normal plot of normal distributed variables (Fig.2). The residuals werefound to be distributed normally. The assumption of constant variance was tested using the Modified Wald test for groupwise heteroscedasticity (Greene, 2000) and the residuals were found to have constant variance. The Woolridge test was used to check for first order auto-correlation (Woolridge, 2002) and the residuals were found to be auto-correlated. The model was re-estimated using the feasible generalized least square method to control for auto-correlation. Another potential problem wasomitted variable bias which mightarise due to the exclusion of factors like pest and diseases that possibly correlated with climate variables. ARAMSEY reset test was used to check for specification bias and the likelihood of model misspecification is rejected. The results of both the FGLS and OLS estimation has been tabulated in Table 2 . Here, the results of the FGLS model are discussed as these estimates are more reliable.

The results revealed that machine labour, human labour and fertilizer application are positively related to wheat yields and their effects were found to be statistically significant. A one percent increase in fertilizer application above mean level resulted in an increase in wheat yields by 0.312 percent. Several studies have reported that intensive application of fertilizers was vital in increasing wheat productivity and bridging yield gaps. The elasticities of machine and human labour are 0.122 and 0.193 per cent respectively. Irrigation was found to be positively related to wheat yields but the relationship was not statistically significant. Similarly, the relation between seed expenses and wheat yields was not statistically significant. The regional dummy variables were statistically significant thereby highlighting the importance of controlling for spatial fixed effects. 


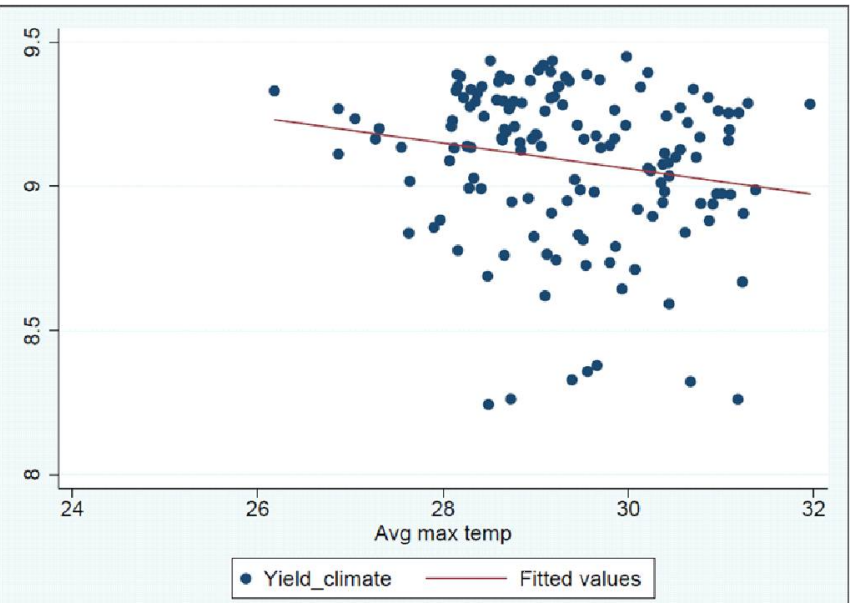

Fig. 1: Correlation between predicted yields and average maximum temperature

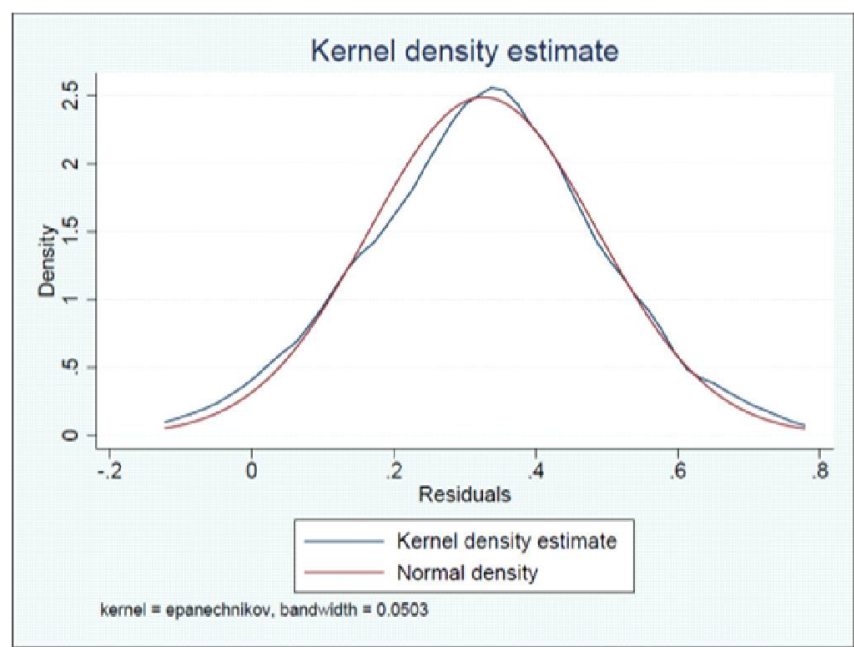

Fig. 2: Kernel density plot of residuals

Table 2: Crop yield function

\begin{tabular}{llllll}
\hline Variable & FGLS & & & OLS & \\
\cline { 2 - 3 } \cline { 5 - 5 } (Dependent variable:Ln_Yield) & Coefficient & Standard Error & & Coefficient & Standard Error \\
\hline Maximum temperature & $-0.030^{* *}$ & 0.013 & $-0.002^{*}$ & 0.034 \\
Minimum temperature & 0.003 & 0.014 & 0.028 & 0.014 \\
Rainfall deviation & $-0.0001^{*}$ & 0.001 & $0.001^{*}$ & 0.001 \\
Ln_Irrigation expenses & 0.047 & 0.036 & 0.004 & 0.030 \\
Ln_Machine Labor expenses & $0.122^{* * * *}$ & 0.033 & -0.033 & 0.026 \\
Ln_Human Labor expenses & $0.193^{* * *}$ & 0.064 & $0.154^{* * *}$ & 0.044 \\
Ln_Fertilizer application & $0.312^{* * *}$ & 0.057 & $0.382^{* * *}$ & 0.048 \\
Ln_Seed expenses & -0.002 & 0.072 & -0.015 & 0.052 \\
Haryana_dummy & $-0.099^{*}$ & 0.057 & -0.066 & 0.048 \\
UP_dummy & $-0.419 * * *$ & 0.062 & $-0.381^{* * *}$ & 0.053 \\
MP_dummy & $-0.572^{* * *}$ & 0.080 & $-0.541^{* * *}$ & 0.072 \\
Rajasthan_dummy & $-0.287^{* * *}$ & 0.081 & $-0.227^{* * *}$ & 0.073 \\
Bihar_dummy & $-0.544^{* * *}$ & 0.077 & $-0.516^{* * *}$ & 0.069 \\
Constant & $5.144^{* * *}$ & 0.713 & $5.094^{* * *}$ & 0.497 \\
Adjusted R2 & 0.954 & 0.937 & & \\
\hline
\end{tabular}

$* * *$ indicates $1 \%$ level of significance, $* *$ indicates $5 \%$ level of significance and $*$ indicates $10 \%$ level of significance

Among the climate variables deviation from normal rainfall levels was found to be detrimental for wheat productivity as anticipated and the relationship was statistically significant. But the magnitude of impact was only marginal indicating that provision of irrigation facilities could be offsetting the impact of rainfall deficits.Although, average minimum temperatures have increased significantly during the study period, the relationship between wheat yields and minimum temperature was not statistically significant. On the other hand, increase in maximum temperature reduced wheat yields and the effects were statistically significant.An increase in maximum temperature (day temperature) by $1{ }^{\circ} \mathrm{C}$ reduced the wheat yield by 3 percent.The negative relationship between wheat yields and average maximum temperature is depicted in Fig. 1, wherein predicted wheat yields are plotted against average maximum temperature. The negative slope of the trend line clearly indicated detrimental impact of rising day temperature 
Table 3: Contribution of various factors to wheat yield growth

\begin{tabular}{llll}
\hline Variables & Elasticity (1) & $\begin{array}{l}\text { Percent change in } \\
\text { explanatory variable (2) }\end{array}$ & $\begin{array}{l}\text { Contribution to } \\
\text { growth }(1)^{*}(2)\end{array}$ \\
\hline Maximum temperature & -0.872 & 7.23 & $-6.30(-10.31)$ \\
Human labour & & 0.193 & $23.7804 .58(7.51)$ \\
Machine labour & 0.122 & 109.13 & $13.28(21.74)$ \\
Fertilizer & 0.312 & 98.34 & $30.65(50.18)$ \\
Residual & - & - & $18.87(30.90)$ \\
Yield & - & 61.09 & $61.09(100)$ \\
\hline
\end{tabular}

on wheat yields. These findings are in line with experimental studies that report strong negative correlation between wheat yields and maximum temperature(Pal and Murthy, 2009; Kumar et al., 2013).

Previous studies reported that the increase in day temperatures is likely to reduce seed germination, seedling growth, tillers number, grains per spike, grain size and number (Asseng et al., 2015; Akther and Islam, 2017). Increased growing season temperatures also reduced the crop duration, grain filling and increased the probability of years with low yields (Zaccharias et al., 2014). Studies using the INFOCROP model for wheat had simulated the potential impact of climate change on wheat yields under various emission scenarios (Kumar et al., 2014). The study revealed that the impact of climate change would be higher in regions with mean seasonal maximum and minimum temperatures in excess of $27^{\circ} \mathrm{C}$ and $13.0^{\circ} \mathrm{C}$ respectively. The projected impacts in wheat yields for 2050 ranged from 6 to 23 per cent without any adaptation strategies. The average maximum temperature in Rabi season is expected to increase by $2.6-4.0^{\circ} \mathrm{C}$ (Birthal et al., 2014). The marginal impactin wheat yieldsfor the projected increase in temperatures using our estimates would range from 7.8 to 12 per cent. The predicted impact from our model fall within the predicted range (Kumar et al.,2014) and wascloser to the lower bound values. Several short term adaptation strategies through input management have been implicitly accounted for in our analysis and could explain the proximity to lower bound values.

Studies based on historical data revealed that the increase in maximum temperature by $1^{\circ} \mathrm{C}$ reduced the wheat yield by 9.2 per cent, while an equal increase in minimum temperature offsets the impact by 3.3 per cent (Birthal et al, . 2014). The predicted net impact of 6 per cent was higher than our estimates. Differences in magnitude might be due to differences in time period of study and cross-sections units used.Moreover, the inclusion of inputs enables us to delineate the impact of climate variables and non-climate variables with greater accuracy in comparison to previous studies.The reduction in wheat yields due to rise in temperature could be attributed to reduction in carbon assimilation due to increased respiratory losses (Kumari et al., 2019), shortening the duration of wheat crop (Patel et al., 2018).

\section{Contribution of non-climate factors to wheat yield growth}

Further, the relative contribution of climatic and nonclimatic factors on wheat yield growth was computed using the growth accounting approach (You et al., 2009). Threeyear averages of yield and inputs which had a significant impact on wheat yield were computed for two time periods, 1981-1983 and 2008-2010. The percentage change in these variables over the study period was calculated. The contribution of each factor to yield growth was computed as the product of percentage change in variable and the elasticity coefficient. The results have been tabulated in Table 3. Wheat yields have risen by 61.10 percent during the study period. Increase in usage of physical inputs is responsible for 79.45 percent increase in wheat yields. Fertilizer usage has been the chief driving factor for increase in wheat yields account for nearly one half of the growth in yield levels. Nearly 22 percent of the yield growth has been attributed to machine labour which is in agreement with previous findings that mechanization of agriculture increases crop productivity. The contribution of non-climate factors to yield growth $(79.45 \%)$ was substantially greater than that of climate factors. This underlines the need to include physical inputs while estimating the response functions of crop yields to climate change.

\section{CONCLUSION}

The study attempts to analyze the impact of climate change on wheat yield using a state level panel data from 1981-2010. The spatial effects are controlled for by use of 
regional dummies. Changes in physical inputs are also accounted for in the panel data regression analysis thereby segregating the effect of climatic and non-climatic factors. Trend analysis of climate variables revealed a significant increase in maximum and minimum temperature in growing season. Increase in average maximum temperature by $1^{\circ} \mathrm{C}$ reduced wheat yields by 3 percent. The impact ofincrease in minimum temperature on wheat yields was not statistically significant.Decomposition of factors influencing wheat yields revealed that non-climatic factors accounted for 79.45 percent of yield growth. Increase in fertilizer application and mechanization were key drivers of wheat yield growth.Further, rise in average maximum temperature has reduced yield growth by 10 percent.

\section{REFERENCES}

Akter, N. and Islam, M.R.(2017). Heat stress effects and management in wheat: Areview. Agron. Sustain. Dev., 37(5): 37-49.

Asseng, S., Ewert, F., Martre, P., Rötter, R.P., Lobell, D.B., Cammarano, D. and Reynolds, M.P. (2015). Rising temperatures reduce global wheat production. Nature Clim. Change., 5(2): 143-147.

Attri, S.D. and Rathore, L.S. (2003).Simulation of impact of projected climate change on wheat in India. Int. $J$. Climatol., 23(6): 693-705.

Birthal, P.S., Khan, T.M., Negi, D.S. and Agarwal, S.(2014). Impact of climate change on yields of major food crops in India: Implications for food security. Agric. Econ. Res. Rev., 27(2): 145-155.

Blanc, E. and Schlenker,W.(2017). The use of panel models in assessments of climate impacts on agriculture. Rev. Environ. Econ. Policy., 11(2): 258-279.

DEFRA(2005).India-UK collaboration on impacts of climate change in India. http://www.defra.gov.uk/ environment/ climatechange/internat/devcountry/india $2 . h t m$ (accessed 18 April 2006).

DES (Directorate of Economics and Statistics). (19802010). Cost of Cultivation of Principal Crops in India (various issues), Government of India, New Delhi.

Deschenes, O. and Greenstone, M. (2007). The Economic Impacts of Climate Change: Evidence from Agricultural Output and Random Fluctuations in Weather, Am. Econ. Rev.,97(1): 354-385.

Greene, W. (2000).Econometric Analysis., Upper Saddle River, NJ: Prentice-Hall.
Gu, L. (2003). Comment on Climate and Management Contributions to Recent Trendsin USAgricultural Yields. Science, 300: 1505-1505.

Howard, A. (1924). Crop production in India: A critical survey of its problems. Oxford Univ. Press, Oxford, UK: 156.

Jalota, S.K., Kaur, H., Ray, S.S., Tripathy, R., Vashisht, B.B. and Bal, S.K. (2013). Past and General Circulation Modeldriven future trends of climate change in Central Indian Punjab: ensuing yield of rice-wheat cropping system. Current Sci., 104(1): 105-110

Jha, B. and Tripathi, A. (2017). How Susceptible Is India's Food Basket to Climate Change? Soc. Change, 47(1): 11-27.

Kumar, K., Singh, S. and Singh, D. (2013). Seasonal climatic variability and its impact assessment on wheat productivity using crop modeling techniques in Haryana. J. Agrometeorol., 15(1): 25-29.

Kumar, S.N.,Aggarwal, P.K., Rani, D.S., Saxena, R., Chauhan, N. and Jain S. (2014).Vulnerability of wheat production to climate change in India. Clim. Res., 59(3): 173-187

Kumari, S., Roy, S.B., Sharma, P., Srivastava, A., Sehgal, V.K. andDhakar, R. (2019). Modeling impacts of climate change on spring wheat in northern India. J.Agrometeorol., 21(2): 123-130.

Mendelsohn, R., Nordhaus, W.D.and Shaw, D. (1994). The Impact of Global Warming on Agriculture: A Ricardian Analysis.Am. Econ. Rev.,84:753-771.

Nelson, G.C., Rosegrant, M.W., Koo, J., Robertson, R., Sulser, T.,Zhu, T., Ringler, C., Msangi, S., Palazzo, A., Batka, M., Magalhaes, M., Valmonte-Santos, R., Ewing, M. and Lee, D.(2009). Climate Change: Impact on Agriculture and Costs of Adaptation.Food Policy Report.International Food Policy Research Institute, Washington, D.C.

Pal, R.K. and Murthy, N.S. (2009).Influence of weather parameters on yield and yield attributes of wheat (Triticumaestivum L.). J. Agrometeorol., 11(1):54-56.

Patel, C., Nema, A.K., Singh, R.S., Yadav, M.K., Singh, K.K., Singh, S.K.andSingh, S.M.(2018). Assessment of climate change impact on wheat crop using MarkSim GCM in Varanasi, Uttar Pradesh. J.Agrometeorol., 20(3):216218.

Porter, J.R. and Gawith, M.(1999). Temperature and the growth and development of wheat: a review. Eur. J. Agron., 10:23-36 
Pramod, V.P., Bapuji Rao, B., Ramakrishna, S.S.V.S., Muneshwar Singh, M., Patel, N.R., Sandeep, V.M., Rao, V.U.M., Santhibhushan Chowdary, P., Narsimha Rao, V. and Vijayakumar, P. (2017). Impact of projected climate on wheat yields in India and its adaptation strategies. $J$. Agrometeorol., 19 (3): 207-216.

Rosenzweig, C. and Parry, M.L. (1994).Potential impact of climate change on world food supply. Nature, 367:133138.

Sendhil, R., Jha, A., Kumar, A. and Singh, S. (2018). Extent of vulnerabilityin wheat producing agro-ecologies of India: Tracking from indicators of cross-section and multidimension data. Ecol. Indic., 89: 771-780.

Swaminathan, M.S.,Rahmaniyan, M., Bertni, C., de Janvry, A., Egziabar, T.G.B., Haddad, L. and Kumar, S.M. (2012). Food securityand climate change. Areport by the High-
Level Panel of Experts on Food Security and Nutrition of the Committee on World Food Security, Food and Agricultural Organization, Rome. June.

Wooldridge, J.M. (2002). Econometric Analysis of Cross Section and Panel Data. Cambridge, MA: MIT Press.

You, L., Rosegrant, M.W., Wood, S.and Sun, D. (2009). Impact of growing season temperature on wheat productivity in China. Agric. For. Meteorol., 149(6): 1009-1014.

Zacharias, M., Naresh Kumar S., Singh, S.D. and Aggarwal P.K. (2014). Assessment of impacts of climate change on rice and wheat in the Indo-Gangetic plains. J.Agrometeorol.,16(1): 9-17. 